\title{
Overexpression of PY1289-HER3 in sporadic pulmonary carcinoid from patients bearing MEN1 gene variants
}

\author{
ROSSANO LATTANZIO ${ }^{1,2}$, SERENA VESCHI ${ }^{1,2}$, GITANA MARIA ACETO ${ }^{1}$, MARIA CRISTINA CURIA ${ }^{1}$, \\ ALESSANDRO CAMA ${ }^{3}$, LAURA DE LELLIS ${ }^{3}$, FABIANA FANTINI ${ }^{1}$, DOMENICO ANGELUCCI ${ }^{4}$, \\ STEFANO IACOBELLI ${ }^{2,5}$, MAURO PIANTELLI ${ }^{1,2,5^{*}}$ and PASQUALE BATTISTA ${ }^{1^{*}}$ \\ ${ }^{1}$ Department of Medical, Oral and Biotechnological Sciences; ${ }^{2}$ Center of Excellence on Aging, \\ University 'G. d'Annunzio' Foundation; ${ }^{3}$ Department of Pharmacy, University 'G. d'Annunzio' - Chieti-Pescara; \\ ${ }^{4}$ Division of Pathology, 'SS Annunziata' Hospital; ${ }^{5}$ Mediapharma s.r.l., I-66010 Chieti, Italy
}

Received May 5, 2015; Accepted April 29, 2016

DOI: $10.3892 / \mathrm{ol} .2016 .4651$

\begin{abstract}
The present study aimed to investigate the expression of human epidermal growth factor receptors (HERs) (HER1/HER2/HER3/HER4) and their phosphorylated forms (p-HER1/p-HER2/p-HER3/p-HER4) in pulmonary carcinoids (PCs). HER and p-HER protein expression was assessed by immunohistochemistry on tissue microarrays in 37 specimens of sporadic PCs, 29 typical carcinoids (TCs) and 8 atypical carcinoids (ACs). When compared with the ACs, the TCs did not exhibit any differences in terms of HER/p-HER expression. The tumors of this study have previously been characterized for the expression of menin and the mutational status of menin 1 (MEN1), a gene strongly implicated in the pathogenesis of PCs. In the present study, it was found that the cytoplasmic ('disarrayed'), but not nuclear ('arrayed') expression of menin was positively correlated with HER3 ( $\mathrm{P}=0.004)$, HER4 $(\mathrm{P}=0.015), \mathrm{p}-\mathrm{HER} 1(\mathrm{P}=0.005)$, p-HER3 $(\mathrm{P}<0.001)$, and p-HER4 $(\mathrm{P}=0.001)$ expression. Moreover, HER3 and p-HER3 were found to be significantly more expressed in PCs with $M E N 1$ variants, than in tumors with MEN1 wild-type $(\mathrm{P}=0.000$ and $\mathrm{P}=0.025$, respectively). These findings suggest the potential clinical use of HER inhibitors in the treatment of patients with PCs, particularly for individuals with p-HER3-positive PCs harboring MEN1 gene variants.
\end{abstract}

Correspondence to: Professor Pasquale Battista, Department of Medical, Oral and Biotechnological Sciences, University 'G. d'Annunzio' - Chieti-Pescara, Via dei Vestini 31, I-66010 Chieti, Italy

E-mail:p.battista@unich.it

${ }^{*}$ Contributed equally

Key words: pulmonary carcinoid, human epidermal growth factor receptors, phosphorylated forms, MEN1

\section{Introduction}

Pulmonary carcinoids (PCs), which account for 2-5\% of all lung primary tumors (1) and are comprised of the typical carcinoid (TC) and atypical carcinoid (AC) types, are components of neuroendocrine neoplasms, a heterogenous group of tumors whose prevalence is increasing (2). TCs, which are up to four times more frequent than ACs, are low-grade tumors characterized by scarce mitotic figures, an absence of necrosis and a lower average size in comparison with ACs. ACs are considered to be intermediate-grade tumors with more mitotic figures than TCs, plus areas of focal necrosis and a greater size than TCs (3). The mean 5-year survival rate for patients with TCs is $88 \%$ and ranges from $25-56 \%$ for ACs (4-6). Surgical resection of the tumor in the affected lung is the standard treatment, but complete surgical excision can be difficult or unattainable depending upon the location of the tumor in the chest and whether it has metastasized. The outcome for patients with widely metastatic disease is poor, and chemotherapy and radiation therapy have limited success in treating PCs (7-9). Several studies designed to identify molecular alterations associated with the development and unpredictable progression of this type of tumor have only been partially successful (10-12). A better understanding of PC biology could lead to the development of novel therapeutic strategies.

The human epidermal growth factor receptor (HER) family, comprising the epidermal growth factor receptor (EGFR; also known as HER1), HER2, HER3 and HER4, is not only essential for the development and maintenance of normal tissue, but is also strongly involved in the development of numerous tumor types $(13,14)$. HER dimerization is required for signal transduction to occur, through formation of homodimeric or heterodimeric complexes. Dimer formation leads to activation of the intrinsic tyrosine kinase domain, followed by phosphorylation on specific tyrosine residues, which serve as docking sites for downstream signaling proteins (15). An increasing number of small molecules and monoclonal antibodies are being recognized as targeting the HER family (15-17).

In the present study, the expression pattern of unphosphorylated (HER) and phosphorylated (p-HER) forms of HER receptors were defined in archival tumor specimens of 37 patients 
with PC tumors ( 29 with TC and 8 with AC), in order to assess the expression of possible molecular targets of anti-HER therapy.

\section{Materials and methods}

Tissue samples. Archived formalin-fixed paraffin-embedded blocks derived from resection material of 37 apparently sporadic PCs consecutively diagnosed between January 2001 and December 2008 at the Institute of Pathology, 'S.S. Annunziata' Hospital (Chieti, Italy) were retrieved. All tumors were reviewed for diagnosis. Cases were classified as TC ( 29 cases) or AC ( 8 cases) according to the World Health Organization classification (18). For each sample, tumor and normal tissues were available. The study was approved by the Ethical Committee of the 'S.S. Annunziata' Hospital.

Tissue microarray (TMA) construction and immunohistochemistry $(I H C)$. Duplicate TMAs were constructed by extracting cores (2-mm in diameter) of histologically confirmed neoplastic areas, as previously described (19). TMA sections were stained using antibodies to HER1 (EGFR PharmDx kit; Dako, Milano, Italy), pY1197-HER1 (rabbit polyclonal, 1:400 dilution; 30-min incubation; Thermo Fisher Scientific Inc., Waltham, MA, USA), HER2 (HercepTest kit; Dako), pY1248-HER2 (clone PN2A; 1:25 dilution; overnight incubation; Dako), HER3 (clone RTJ1; 1:20 dilution; overnight incubation; Novocastra; Leica Microsystems, Milano, Italy), pY1289-HER3 (clone 21D3; 1:50 dilution; overnight incubation; Cell Signaling Technology Inc., Danvers, MA, USA), HER4 (rabbit polyclonal; 1:50 dilution; overnight incubation; Santa Cruz Technology Inc., Dallas, TX, USA) and pY1162-HER4 (rabbit monoclonal; 1:100 dilution; overnight incubation; Epitomics/Abcam, Cambridge, UK). Epitope retrieval was performed in a heated citrate buffer (pH 6.0) for p-HER2, HER3, HER4 and p-HER4, and in $1 \mathrm{mmol} / \mathrm{l}$ EDTA ( $\mathrm{pH}$ 8.0) for $\mathrm{p}$-HER3. Antigen-antibody reactions were visualized using a polymer-based detection system (EnVision kit; Dako), using diaminobenzidine as a chromogen. The expression of HER1 and HER2 was evaluated according to the manufacturer's protocols (EGFR PharmDx and HercepTest Dako kits, respectively). Appropriate positive controls (HER1, EGFR PharmDx control slide; HER2, HER2 HercepTest control slide; HER3, HER4, p-HER1, p-HER2 and p-HER4, breast cancer tissue; and p-HER3, lung cancer tissue) of human tumor tissues known to express the marker of interest were used. For negative control sections, the specific primary antibody was omitted or replaced with non-immune serum or isotype-matched immunoglobulins. The expression of markers was quantified as a percentage of the immunoreactive tumor cells. Cases were considered HER-positive when $\geq 1 \%$ of tumor cells were positively stained (PharmDx kit; Dako, Milano, Italy).

Statistical analysis. Comparisons between molecular markers were performed using Spearman's Rho correlation. Student's t-test was used to evaluate the statistical differences between markers (HER and p-HER) in PC according to the MENI gene status and the tumor histotype (TC and AC). SPSS version 15.0 (SPSS Inc., Chicago, IL, USA) was employed throughout, and $\mathrm{P}<0.05$ was considered to indicate a statistically significant difference.

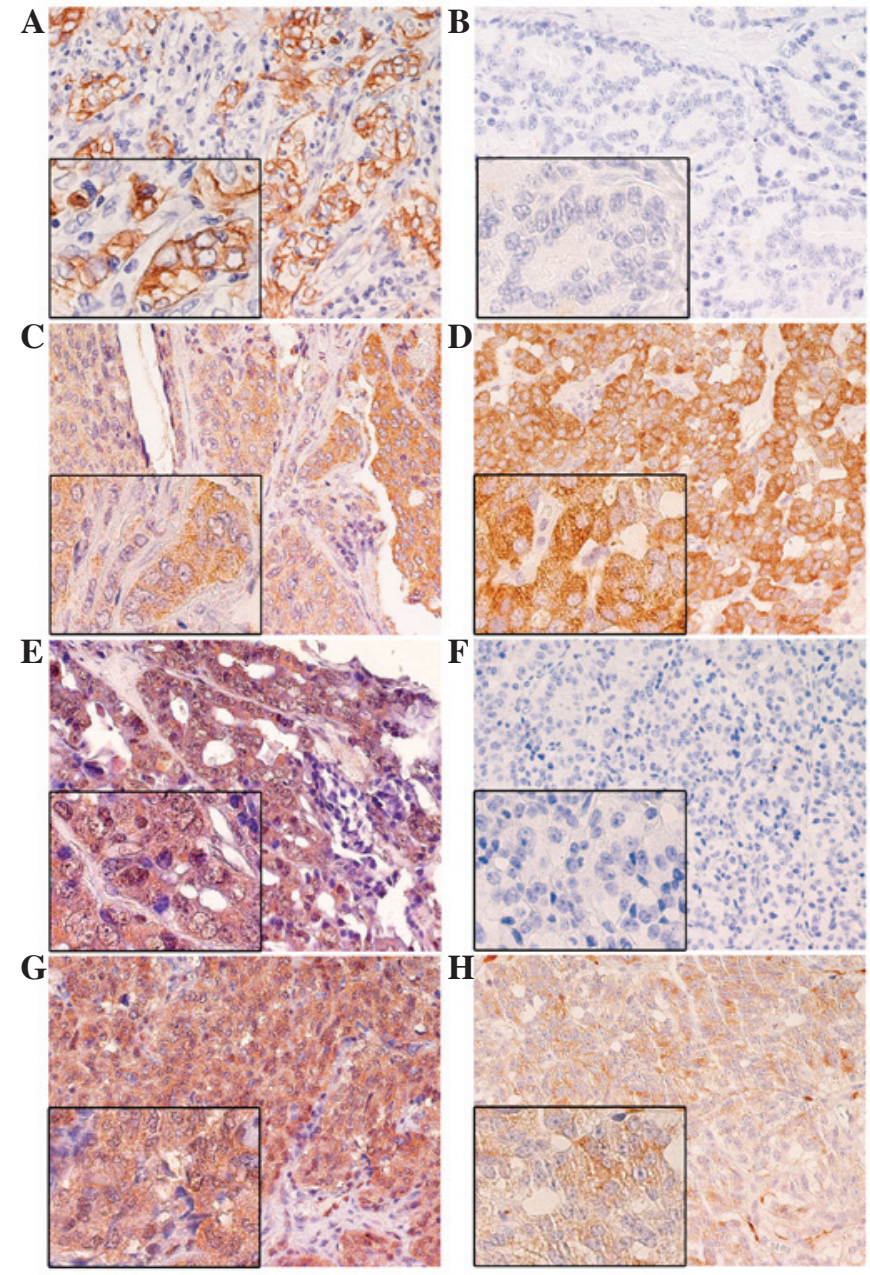

Figure 1. HER and p-HER immunostaining patterns in pulmonary carcinoids. (A) Membrane staining for HER1; (B) absence of HER2 reactivity; (C) HER3 and (D) HER4 cytoplasmic expression; (E) p-HER1 cytoplasmic expression with tumor cells showing concomitant nuclear staining; (F) lack of expression for p-HER2; (G) p-HER3 cytoplasmic expression with tumor cells showing concomitant faint nuclear staining; and $(\mathrm{H})$ p-HER4 cytoplasmic expression. Inset images (magnification, x640) show enlargements of reported images (magnification, x400). HER, human epidermal growth factor receptor; p-HER, phosphorylated HER.

\section{Results}

Immunoreactivity for HER1 was present mainly in the tumor cell membranes. Reactivity for HER2 and p-HER2 receptors was absent in all samples. Specific positive staining for HER3 and HER4 was exclusively found in the cytoplasm of the tumor cells (Fig. 1). p-HER1 and p-HER3 were mainly detected in the cytoplasm. However, in association with cytoplasmic expression, nuclear staining for $\mathrm{p}-\mathrm{HER} 1$ and $\mathrm{p}-\mathrm{HER} 3$ was also observed in a small proportion of tumor cells [mean \pm standard error (SE), $6.3 \pm 4.1$ and $2.3 \pm 1.0 \%$, respectively]. For analytical purposes, only cytoplasmic expression for p-HER1 and p-HER3 was considered.

The analysis showed that $65.5 \%$ of TC and $50.0 \%$ of $\mathrm{AC}$ tumors expressed HER1. HER3-positive tumors occurred in 79.3 and $100 \%$ of TC and $\mathrm{AC}$ cases, respectively, while HER4-positive tumors occurred in 82.8 and $87.5 \%$, respectively. In the cases of TC, the following proportions of positive tumors were recorded; $51.7 \%$ for p-HER1, $75.9 \%$ for p-HER3 
Table I. Expression of HER markers and their activated forms in pulmonary carcinoids.

\begin{tabular}{lcccc}
\hline Marker $^{\mathrm{a}}$ & All cases $(\mathrm{n}=37)$ & Typical carcinoids $(\mathrm{n}=29)$ & Atypical carcinoids $(\mathrm{n}=8)^{\text {P-value }}{ }^{\mathrm{b}}$ \\
\hline HER1 & $22.2 \pm 5.6$ & $19.0 \pm 5.8$ & $33.0 \pm 14.6$ & 0.296 \\
HER2 & $0.0 \pm 0.0$ & $0.0 \pm 0.0$ & $0.0 \pm 0.0$ & $57.0 \pm 11.0$ \\
HER3 & $58.0 \pm 6.2$ & $56.9 \pm 7.5$ & $62.0 \pm 11.1$ & 0.690 \\
HER4 & $62.5 \pm 5.9$ & $62.6 \pm 7.0$ & $38.7 \pm 16.5$ & 0.966 \\
p-HER1 & $36.8 \pm 8.1$ & $36.0 \pm 9.6$ & $0.0 \pm 0.0$ & 0.884 \\
p-HER2 & $0.0 \pm 0.0$ & $0.0 \pm 0.0$ & $25.5 \pm 11.2$ & 0.370 \\
p-HER3 & $35.0 \pm 6.4$ & $38.7 \pm 7.8$ & $17.7 \pm 11.5$ & 0.849 \\
p-HER4 & $19.4 \pm 5.4$ & $20.1 \pm 6.2$ & \\
\hline
\end{tabular}

${ }^{a}$ Results are expressed as the mean percentage of positive tumor cells \pm standard error; ${ }^{\mathrm{b}} \mathrm{TCs}$ vs. ACs, P-values from independent-samples t-test. HER, human epidermal growth factor receptor; p-HER, phosphorylated HER; TC, typical carcinoid; AC, atypical carcinoid.

Table II. Correlations ${ }^{\mathrm{a}}$ among HER and p-HER expression (percentage values) in pulmonary carcinoids.

\begin{tabular}{|c|c|c|c|c|c|c|}
\hline Marker & HER1 & HER3 & HER4 & p-HER1 & p-HER3 & p-HER4 \\
\hline \multicolumn{7}{|l|}{ HER1 } \\
\hline rho & 1.000 & 0.003 & -0.088 & 0.367 & 0.067 & 0.292 \\
\hline P-value & & 0.987 & 0.615 & 0.078 & 0.734 & 0.177 \\
\hline \multicolumn{7}{|l|}{ HER3 } \\
\hline rho & 0.003 & 1.000 & $0.493^{b}$ & 0.392 & $0.687^{\mathrm{b}}$ & $0.495^{\mathrm{b}}$ \\
\hline P-value & 0.987 & & $0.002^{\mathrm{b}}$ & 0.058 & $0.000^{\mathrm{b}}$ & $0.014^{\mathrm{b}}$ \\
\hline \multicolumn{7}{|l|}{ HER4 } \\
\hline rho & -0.088 & $0.493^{b}$ & 1.000 & $0.482^{\mathrm{b}}$ & $0.508^{b}$ & $0.550^{\mathrm{b}}$ \\
\hline P-value & 0.615 & $0.002^{\mathrm{b}}$ & & $0.017^{\mathrm{b}}$ & $0.005^{\mathrm{b}}$ & $0.005^{\mathrm{b}}$ \\
\hline \multicolumn{7}{|l|}{ p-HER 1} \\
\hline rho & 0.367 & 0.392 & $0.482^{b}$ & 1.000 & $0.535^{\mathrm{b}}$ & $0.882^{\mathrm{b}}$ \\
\hline P-value & 0.078 & 0.058 & $0.017^{\mathrm{b}}$ & & $0.009^{\mathrm{b}}$ & $0.000^{\mathrm{b}}$ \\
\hline \multicolumn{7}{|l|}{ p-HER3 } \\
\hline rho & 0.067 & $0.687^{b}$ & $0.508^{b}$ & $0.535^{\mathrm{b}}$ & 1.000 & $0.728^{b}$ \\
\hline P-value & 0.734 & $0.000^{\mathrm{b}}$ & $0.005^{\mathrm{b}}$ & $0.009^{\mathrm{b}}$ & & $0.000^{\mathrm{b}}$ \\
\hline \multicolumn{7}{|l|}{ p-HER4 } \\
\hline rho & 0.292 & $0.495^{\mathrm{b}}$ & $0.550^{\mathrm{b}}$ & $0.882^{\mathrm{b}}$ & $0.728^{b}$ & 1.000 \\
\hline P-value & 0.177 & $0.014^{\mathrm{b}}$ & $0.005^{\mathrm{b}}$ & $0.000^{\mathrm{b}}$ & $0.000^{\mathrm{b}}$ & \\
\hline
\end{tabular}

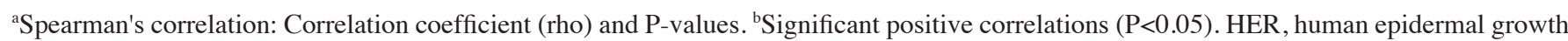
factor receptor; p-HER, phosphorylated HER.

and $48.3 \%$ for $\mathrm{p}$-HER4. In the cases of $\mathrm{AC}$, the proportions of positive tumors were as follows: $62.5 \%$ for p-HER1, $62.5 \%$ for p-HER3 and $37.5 \%$ for p-HER4. The distribution of HER and p-HER expression is reported as a box-and-whisker plot in Fig. 2.

The expression (mean $\% \pm \mathrm{SE}$ ) of the HERs and their activated forms, in all cases and in TC vs. AC tumor types, are reported in Table I. As assessed by independent-samples t-test, the TCs and ACs did not significantly differ in terms of HER/p-HER expression.

By Spearman's correlation analysis of the expression of HERs and p-HERs in PCs (Table II), HER3 expression was found to be positively correlated with that of HER4 (rho=0.493; $\mathrm{P}=0.002)$, p-HER3 (rho=0.687; $\mathrm{P}<0.001)$ and $\mathrm{p}$-HER4 (rho=0.495; $\mathrm{P}=0.014)$. The expression of HER4 was also directly correlated with that of $\mathrm{p}-\mathrm{HER} 1(\mathrm{rho}=0.482 ; \mathrm{P}=0.017)$, p-HER3 (rho=0.508; $\mathrm{P}=0.005$ ) and p-HER4 (rho=0.550; $\mathrm{P}=0.005)$. In addition, significant direct correlations were found between p-HER3 and p-HER1 (rho=0.535; $\mathrm{P}=0.009$ ), p-HER3 and p-HER4 (rho=0.728; P<0.001), and p-HER4 and p-HER1 (rho=0.882; P<0.001) (Table II).

PC samples utilized in this study have previously been characterized for the expression of menin and the mutational status of the MEN1 gene (20). Therefore, in the present study, 
Table III. Correlations ${ }^{\mathrm{a}}$ among menin and HER/p-HER expression (percentage values) in pulmonary carcinoids

\begin{tabular}{lcccccccc}
\hline Localization & n-menin & c-menin & HER1 & HER3 & HER4 & p-HER1 & p-HER3 & p-HER4 \\
\hline $\begin{array}{l}\text { n-menin } \\
\text { rho }\end{array}$ & 1.000 & -0.059 & -0.046 & 0.073 & 0.167 & -0.066 & -0.233 & -0.073 \\
$\begin{array}{l}\text { P-value } \\
\text { c-menin }\end{array}$ & & 0.723 & 0.792 & 0.668 & 0.323 & 0.759 & 0.224 & 0.736 \\
$\quad$ rho & -0.059 & 1.000 & -0.094 & $0.457^{\mathrm{b}}$ & $0.398^{\mathrm{b}}$ & $0.551^{\mathrm{b}}$ & $0.641^{\mathrm{b}}$ & $0.635^{\mathrm{b}}$ \\
P-value & 0.723 & & 0.592 & $0.004^{\mathrm{b}}$ & $0.015^{\mathrm{b}}$ & $0.005^{\mathrm{b}}$ & $0.000^{\mathrm{b}}$ & $0.001^{\mathrm{b}}$ \\
\hline
\end{tabular}

${ }^{a}$ Spearman's correlation: Correlation coefficient (rho) and P-values. ${ }^{b}$ Significant positive correlations $(\mathrm{P}<0.05)$. n-menin, nuclear menin; c-menin, cytoplasmic menin. HER, human epidermal growth factor receptor; p-HER, phosphorylated HER.

Table IV. Expression of HERs and their activated forms in pulmonary carcinoids according to MEN1 gene status.

\begin{tabular}{|c|c|c|c|c|c|c|}
\hline \multirow[b]{2}{*}{ Markers } & \multicolumn{2}{|c|}{ All cases } & \multicolumn{2}{|c|}{ Typical carcinoids } & \multicolumn{2}{|c|}{ Atypical carcinoids } \\
\hline & Mean \pm SE & P-value & Mean \pm SE & P-value & Mean \pm SE & $\mathrm{P}$-value \\
\hline \multicolumn{7}{|l|}{ HER 1} \\
\hline MENI variants & $18.6 \pm 9.1$ & 0.648 & $18.4 \pm 10.9$ & 0.949 & $19.0 \pm 19.0$ & 0.379 \\
\hline MEN1 wild-type & $24.0 \pm 7.1$ & & $19.2 \pm 7.0$ & & $47.0 \pm 22.6$ & \\
\hline \multicolumn{7}{|l|}{ HER3 } \\
\hline MEN1 variants & $84.8 \pm 5.4$ & $0.000^{\mathrm{a}}$ & $85.1 \pm 7.0$ & $0.001^{\mathrm{a}}$ & $84.0 \pm 9.3$ & $0.012^{\mathrm{a}}$ \\
\hline MEN1 wild-type & $43.5 \pm 7.7$ & & $44.2 \pm 9.1$ & & $40.0 \pm 8.1$ & \\
\hline \multicolumn{7}{|l|}{ HER4 } \\
\hline MEN1 variants & $79.5 \pm 4.8$ & $0.009^{\mathrm{a}}$ & $79.6 \pm 6.5$ & $0.039^{\mathrm{a}}$ & $79.3 \pm 6.8$ & 0.156 \\
\hline MENI wild-type & $53.3 \pm 8.2$ & & $55.0 \pm 9.3$ & & $44.8 \pm 18.3$ & \\
\hline \multicolumn{7}{|l|}{ p-HER1 } \\
\hline MEN1 variants & $45.9 \pm 15.7$ & 0.443 & $57.5 \pm 23.1$ & 0.226 & $34.3 \pm 22.9$ & 0.785 \\
\hline MENI wild-type & $32.3 \pm 9.5$ & & $29.4 \pm 10.2$ & & $44.7 \pm 28.6$ & \\
\hline \multicolumn{7}{|l|}{ p-HER3 } \\
\hline MEN1 variants & $54.5 \pm 8.5$ & $0.025^{\mathrm{a}}$ & $59.7 \pm 9.5$ & $0.045^{\mathrm{a}}$ & $46.8 \pm 16.7$ & $0.046^{\mathrm{a}}$ \\
\hline MEN1 wild-type & $24.8 \pm 7.9$ & & $30.3 \pm 9.5$ & & $4.3 \pm 2.5$ & \\
\hline \multicolumn{7}{|l|}{ p-HER4 } \\
\hline$M E N 1$ variants & $26.6 \pm 9.9$ & 0.354 & $25.5 \pm 9.0$ & 0.643 & $27.8 \pm 19.3$ & 0.358 \\
\hline MEN1 wild-type & $15.8 \pm 6.5$ & & $18.4 \pm 7.8$ & & $4.3 \pm 4.3$ & \\
\hline
\end{tabular}

Data are presented as the mean percentage of positive tumor cells \pm standard error, with P-values from independent-samples t-test. ${ }^{\text {a Significant }}$ positive correlations $(\mathrm{P}<0.05)$. HER, human epidermal growth factor receptor; p-HER, phosphorylated HER; MEN1, menin 1.

possible correlations were searched for among the expression results of the HERs/p-HERs and that of menin, by Spearman's rho test. As reported in Table III, the cytoplasmic but not the nuclear expression of menin was positively correlated with HER3 (rho=0.457; $\mathrm{P}=0.004)$, HER4 (rho=0.398; $\mathrm{P}=0.015$ ), p-HER1 (rho=0.551; $\mathrm{P}=0.005)$, p-HER3 (rho=0.641; $\mathrm{P}<0.001)$, and $\mathrm{p}-\mathrm{HER} 4(\mathrm{rho}=0.635 ; \mathrm{P}=0.001)$ expression.

Table IV shows the expression of HERs and their activated forms according to MEN1 gene status. By independent-sample t-test, HER3 and p-HER3 were found to be significantly more expressed in PCs with MEN1 variants than in tumors with the MEN1 wild-type $(\mathrm{P}=0.000$ and $\mathrm{P}=0.025$, respectively). This was true for the TCs and the ACs. HER4, but not its activated form, was also found to be more expressed in PC tumors $(\mathrm{P}=0.009)$ with $M E N 1$ variants. No statistical significances were found between $M E N 1$ status and the expression levels of HER1 and p-HER1 (Table IV).

\section{Discussion}

HER1 is the first member of the HER family to be identified in PCs, and the existence of an autocrine growth-promoting circuit based on HER1 and transforming growth factor- $\alpha$ has previously been documented $(21,22)$. Lack of HER2 expression in PCs was first observed by Wilkinson et al (23). More recently, Rickman et al (12) investigated a series of PCs by IHC analysis 


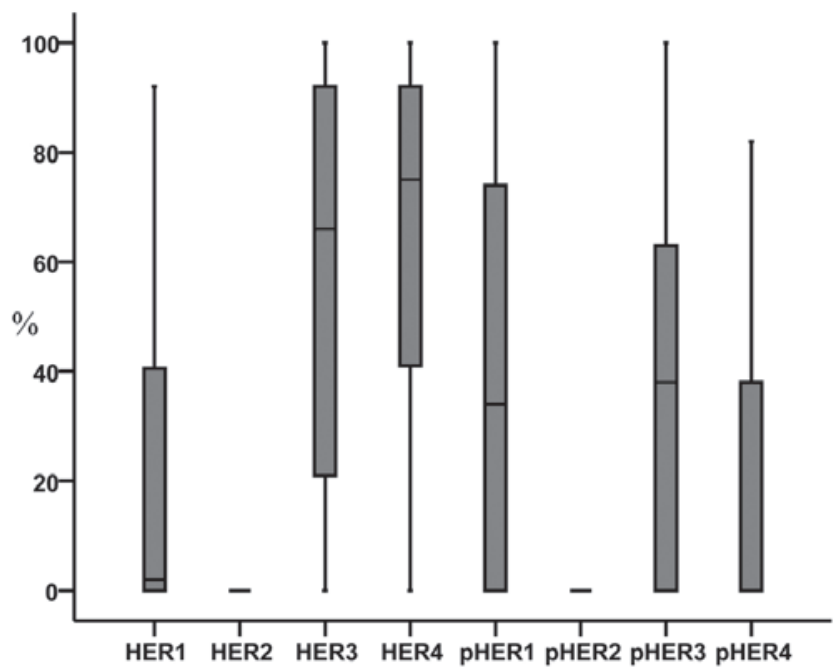

Figure 2. Box-and-whisker diagram of the percentage of pulmonary carcinoid cells stained with anti-HER and anti-p-HER antibodies. Upper and lower ends of boxes represent the 75th and 25th percentiles, respectively. The median value is shown as a solid line. HER, human epidermal growth factor receptor; p-HER, phosphorylated HER.

performed in TMAs to detect the expression of the HER family, and found that $46 \%$ of TCs and $28 \%$ of ACs expressed HER1, while none expressed HER2 and $100 \%$ showed intense to moderate staining for HER3 and HER4. The present study is the first report including data on the expression of p-HER forms. Notably PCs were found to express HER1, HER3 and HER4 receptors, as well as their phosphorylated forms.

Several malignancies, including lung, breast, stomach, colorectal, head and neck, and pancreatic carcinomas, and glioblastoma, melanoma and ovarian cancers, are associated with the mutation or increased expression of members of the HER family. HER3 is the only member of this receptor tyrosine kinase family that does not have intrinsic kinase activity, but is unexpectedly the most robust signaling complex of the HER family (17). Different degrees of HER3 expression have been observed in lung, breast, ovarian, prostate, gastric and colorectal cancer, and high expression usually correlates with a poor prognosis (24). HER2 is unlikely to be the catalytic partner of HER3, as HER2 expression is low or absent in the majority of melanomas. HER3 may function as an allosteric activator of HER1 or HER4 in melanomas (25) and PCs, as suggested by the observation that HER2 is absent in these tumors. In addition, the present study found that the expression of activated HER3 was directly correlated with that of activated HER1 and HER4. The role of HER4 in tumorigenesis is complex and not completely understood. In a breast cancer study, HER4 expression was found to be correlated with a favorable prognosis (26). By contrast, non-small cell lung cancer patients with tumors that expressed HER4 experienced decreased survival times compared with patients with tumors that did not express HER4, and a positive correlation was also found with lymph node metastasis and HER4 expression (27).

The MEN1 gene is implicated in the pathogenesis of hereditary and sporadic PCs, and MEN1 gene mutations are associated with a poor prognosis in these tumors (28). This association with poor prognosis appears to be specific to PCs, as it is not observed in pancreatic neuroendocrine tumors (29).
Menin, the protein encoded by the MEN1 gene, is a component of histone methyltransferase complexes and is ubiquitously expressed $(18,30)$. We previously observed that PCs displaying MEN1 nucleotide variants were characterized by higher menin accumulation in the cytoplasm (disarrayed distribution), but not in the nucleus, compared with those without MEN1 variants (20). In the pancreas, IHC staining for menin showed that normal islet cells exhibited intense nuclear and extremely faint cytoplasmic staining, while $40 \%$ of pancreatic endocrine tumors lacked nuclear immunostaining and expressed high levels of cytoplasmic menin (31). The present study results showed that the presence of the activated HER1, HER3 and HER4 forms was directly correlated with the disarrayed cytoplasmic menin expression, and more importantly, that higher proportions of p-HER3-positive cells are present in PCs harboring MEN1 variants when compared with the wild-type counterpart. The association between HERs and the aberrant cytoplasmic expression of menin in tumors with MEN1 variants is noteworthy, and future studies may address this observation. At present, several HER3-targeting drugs are being tested in clinical trials (16)

Thus, the inhibition of HER signaling in these tumors by monoclonal antibodies or small tyrosine kinase inhibitors may represent a potential therapeutic strategy in the treatment of patients with p-HER-positive tumors, particularly for those patients whose cancer cannot be surgically resected, or in patients with advanced disease. In particular, HER3 could constitute a relevant therapeutic target in patients with MEN1 gene variants. The present study findings may have clinical implications for the treatment of patients with PCs.

\section{Acknowledgements}

This study was supported by the Italian Association for Cancer Research, and by the Italian Ministry of Education, University and Research.

\section{References}

1. Bini A, Brandolini J, Cassanelli N, Davoli F, Dolci G, Sellitri F and Stella F: Typical and atypical pulmonary carcinoids: Our institutional experience. Interact Cardiovasc Thorac Surg 7: 415-418, 2008.

2. Grozinsky-Glasberg S and Pavel M: Inhibition of mTOR in carcinoid tumors. Target Oncol 7: 189-195, 2012.

3. Travis WD, Rush W, Flieder DB, Falk R, Fleming MV, Gal AA and Koss MN: Survival analysis of 200 pulmonary neuroendocrine tumors with clarification of criteria for atypical carcinoid and its separation from typical carcinoid. Am J Surg Pathol 22: 934-944, 1998.

4. Cardillo G, Sera F, Di Martino M, Graziano P, Giunti R, Carbone L, Facciolo F and Martelli M: Bronchial carcinoid tumors: Nodal status and long-term survival after resection. Ann Thorac Surg 77: 1781-1785, 2004.

5. Rugge M, Fassan M, Clemente R, Rizzardi G, Giacomelli L, Pennelli G, Mescoli C, Segat D and Rea F: Bronchopulmonary carcinoid: Phenotype and long-term outcome in a single-institution series of italian patients. Clin Cancer Res 14: 149-154, 2008.

6. Thomas CF Jr, Tazelaar HD and Jett JR: Typical and atypical pulmonary carcinoids: Outcome in patients presenting with regional lymph node involvement. Chest 119: 1143-1150, 2001.

7. Chakravarthy A and Abrams RA: Radiation therapy in the management of patients with malignant carcinoid tumors. Cancer 75: 1386-1390, 1995. 
8. Jodrell DI and Smith IE: Carboplatin in the treatment of metastatic carcinoid tumours and paraganglioma: A phase ii study Cancer Chemother Pharmacol 26: 62-64, 1990.

9. Saltz L, Lauwers G, Wiseberg J and Kelsen D: A phase II trial of carboplatin in patients with advanced APUD tumors. Cancer 72 : 619-622, 1993.

10. Leotlela PD, Jauch A, Holgreve-Grez A and Thakker RV: Genetics of neuroendocrine and carcinoid tumours. Endocr Relat Cancer 10: 437-450, 2003.

11. Forde PM, Hooker CM, Boikos SA, Petrini I, Giaccone G, Rudin CM, Yang SC, Illei PB, Hann CL, Ettinger DS, et al: Systmic therapy, clinical outcomes, and overall survival in locally advanced or metastatic pulmonary carcinoid: A brief report. J Thorac Oncol 9: 414-418, 2014.

12. Rickman OB, Vohra PK, Sanyal B, Vrana JA, Aubry MC, Wigle DA and Thomas CF Jr: Analysis of erbb receptors in pulmonary carcinoid tumors. Clin Cancer Res 15: 3315-3324, 2009.

13. Campbell MR, Amin D and Moasser MM: Her3 comes of age: New insights into its functions and role in signaling, tumor biology, and cancer therapy. Clin Cancer Res 16: 1373-1383, 2010

14. Lemmon MA and Schlessinger J: Cell signaling by receptor tyrosine kinases. Cell 141: 1117-1134, 2010.

15. Roskoski R Jr: ErbB/HER protein-tyrosine kinases: Structures and small molecule inhibitors. Pharmacol Res 87: 42-59, 2014

16. Kol A, Terwisscha van Scheltinga AG, Timmer-Bosscha $\mathrm{H}$ Lamberts LE, Bensch F, de Vries EG and Schröder CP: HER3, serious partner in crime: Therapeutic approaches and potential biomarkers for effect of HER3-targeting. Pharmacol Ther 143: $1-11,2014$.

17. Roskoski R Jr: The ErbB/her family of protein-tyrosine kinases and cancer. Pharmacol Res 79: 34-74, 2014.

18. Travis WD, Brambila E, Müller-Hermelink HK and Harris CC (eds): World Health Organization Classification of Tumours. Pathology and Genetics. Tumours of the Lung, Pleura, Thymus and Heart. IARC Press, Lyon, 2004

19. Lattanzio R, Marchisio M, La Sorda R, Tinari N, Falasca M, Alberti S, Miscia S, Ercolani C,Di Benedetto A,PerracchioL, et al: Overexpression of activated phospholipase $C \gamma 1$ is a risk factor for distant metastases in T1-T2, N0 breast cancer patients undergoing adjuvant chemotherapy. Int J Cancer 132: 1022-1031, 2013.

20. Veschi S, Lattanzio R, Aceto GM, Curia MC, Magnasco S, Angelucci D, Cama A, Piantelli M and Battista P: Alterations of MEN1 and E-cadherin/ $\beta$-catenin complex in sporadic pulmonary carcinoids. Int J Oncol 41: 1221-1228, 2012.
21. Battista P, Pizzicannella G, Vitullo P, Palmirotta R and Mariani-Costantini R: The epidermal growth factor family in pulmonary carcinoids: Immunohistochemical evidence of growth-promoting circuits. Mod Pathol 6: 162-166, 1993.

22. Rusch VW, Klimstra DS and Venkatraman ES: Molecular markers help characterize neuroendocrine lung tumors. Ann Thorac Surg 62: 798-810, 1996.

23. Wilkinson N, Hasleton PS, Wilkes S and Quigley A: Lack of C-erbB-2 protein expression in pulmonary carcinoid tumours. J Clin Pathol 44: 343, 1991.

24. Amin DN, Campbell MR and Moasser MM: The role of HER3, the unpretentious member of the HER family, in cancer biology and cancer therapeutics. Semin Cell Dev Biol 21: 944-950, 2010

25. Ueno Y, Sakurai H, Tsunoda S, Choo MK, Matsuo M, Koizumi K and Saiki I: Heregulin-induced activation of ErbB3 by EGFR tyrosine kinase activity promotes tumor growth and metastasis in melanoma cells. Int J Cancer 123: 340-347, 2008.

26. Sundvall M, Iljin K, Kilpinen S, Sara H, Kallioniemi OP and Elenius K: Role of ErbB4 in breast cancer. J Mammary Gland Biol Neoplasia 13: 259-268, 2008.

27. Starr A, Greif J, Vexler A, Ashkenazy-Voghera M, Gladesh V, Rubin C, Kerber G, Marmor S, Lev-Ari S, Inbar M, et al: ErbB4 increases the proliferation potential of human lung cancer cells and its blockage can be used as a target for anti-cancer therapy. Int J Cancer 119: 269-274, 2006.

28. Swarts DR, Scarpa A, Corbo V, Van Criekinge W, van Engeland M, Gatti G, Henfling ME, Papotti M, Perren A, Ramaekers FC, et al: Men1 gene mutation and reduced expression are associated with poor prognosis in pulmonary carcinoids. J Clin Endocrinol Metab 99: E374-E378, 2014.

29. Swarts DR, Claessen SM, Jonkers YM, van Suylen RJ, Dingemans AM, de Herder WW, de Krijger RR, Smit EF, Thunnissen FB, Seldenrijk CA, et al: Deletions of 11q22.3-q25 are associated with atypical lung carcinoids and poor clinical outcome. Am J Pathol 179: 1129-1137, 2011.

30. Matkar S, Thiel A and Hua X: Menin: A scaffold protein that controls gene expression and cell signaling. Trends Biochem Sci 38: 394-402, 2013

31. Corbo V, Dalai I, Scardoni M, van Suylen RJ, Dingemans AM, de Herder WW, de Krijger RR, Smit EF, Thunnissen FB, Seldenrijk CA, et al: Men1 in pancreatic endocrine tumors: Analysis of gene and protein status in 169 sporadic neoplasms reveals alterations in the vast majority of cases. Endocr Relat Cancer 17: 771-783, 2010. 